\title{
Hypoalbuminemia linked to myocardial dysfunction in recent-onset nephrotic syndrome: a cross-sectional case control 3DSTE study
}

Antoine AbdelMassih ${ }^{1,2^{*}}$, Mervat Haroun ${ }^{3}$, Mohamed Samir ${ }^{1}$, Samar Younis ${ }^{4}$, Martina Tamer ${ }^{4}$ and Amr Salem ${ }^{5}$

\begin{abstract}
Background: Although myocardial dysfunction in the context of longstanding steroid-resistant nephrotic syndrome (NS) has been the focus of many series, the detection of myocardial involvement in recent-onset NS has not taken sufficient attention. The primary outcome parameter of our study is the detection of myocardial dysfunction in the initial episode of NS (first 4 weeks after the onset), while the secondary outcome parameter is the determination of the best predictor of such dysfunction among systolic blood pressure, diastolic blood pressure, the duration of the initial episode of NS, and biochemical parameters such as serum albumin and cholesterol.

Methods: Forty NS patients during the initial episode of NS (first 4 weeks from the onset) were examined for anthropometric data as well as for serum albumin and cholesterol. Motion-mode echocardiography was used to determine Fractional shortening, while 3D echocardiography was applied to determine left ventricular (LV) ejection fraction (EF) and GLS (global longitudinal strain). Finally, we employed combined conventional and tissue doppler to determine LV E/e' ratio (ratio of early transmitral inflow and average early diastolic basal septal and mitral annular velocities). Forty healthy, age- and sex-matched controls were enrolled to control advanced echocardiographic parameters.

Results: LV GLS was markedly reduced in cases compared to controls, denoting subtle systolic dysfunction, while, LV E/e' ratio was significantly higher in cases denoting diastolic dysfunction in early NS. Hypoalbuminemia was found to be the best predictor of both LV GLS and LV E/e' ratio.

Conclusion: Myocardial dysfunction should be considered in any NS patient even in recent-onset NS, the severity of hypoalbuminemia seems to be the best determinant of this dysfunction either by increasing endothelial dysfunction or through triggering inflammation. Further studies are needed on the mechanism by which hypoalbuminemia induces myocardial dysfunction in NS patients
\end{abstract}

Keywords: Recent-onset nephrotic syndrome, Myocardial dysfunction, Hypoalbuminemia

\footnotetext{
* Correspondence: antoine.abdelmassih@kasralainy.edu.eg

'Pediatrics Department, Pediatric Cardiology unit, Faculty of Medicine, Cairo

University, Manial Street, Cairo, Egypt

${ }^{2}$ Pediatric Cardio-Oncology Department, Children Cancer Hospital of Egypt,

Cairo, Egypt

Full list of author information is available at the end of the article
}

\section{Springer Open}

(c) The Author(s). 2021 Open Access This article is licensed under a Creative Commons Attribution 4.0 International License, which permits use, sharing, adaptation, distribution and reproduction in any medium or format, as long as you give appropriate credit to the original author(s) and the source, provide a link to the Creative Commons licence, and indicate if changes were made. The images or other third party material in this article are included in the article's Creative Commons licence, unless indicated otherwise in a credit line to the material. If material is not included in the article's Creative Commons licence and your intended use is not permitted by statutory regulation or exceeds the permitted use, you will need to obtain permission directly from the copyright holder. To view a copy of this licence, visit http://creativecommons.org/licenses/by/4.0/. 


\section{Background}

Nephrotic syndrome (NS) is a clinical condition characterized by massive proteinuria, hypoalbuminemia, hypercholesterolemia, and generalized edema. It is the most common renal disease of childhood with normal renal function [1].

Nephrotic syndrome (NS) is associated with increased cardiovascular morbidity and mortality, the appearance of which is related to excessive loss of albumin in urine, oxidative stress, or steroid therapy (leading to obesity, glucose utilization disorders, and increased arterial hypertension). Moreira-Rodrigues and colleagues describe the occurrence of impaired left ventricular function in the murine model of nephrotic syndrome [2]. The report links the occurrence of such dysfunction to the upregulation of cytokines and chronic inflammation. Furthermore, Hara et al. linked proteinuria to hyperinflammation in the context of Hodgkin disease. Proteinuria may therefore be an important factor in the development of chronic inflammation in NS with subsequent myocardial involvement [3].

The shortest use of steroids can lead to myocardial complications as demonstrated by Shokr et al. who described a case of ST elevation myocardial infarction after a short course of dexamethasone. This may be explained by the role of steroids in impairing myocardial oxygen and glucose uptake. Moreover, their prolonged use can increase systemic blood pressure leading to pressure overload on the cardiomyocytes [4].

To our knowledge, there is no single report to date about myocardial involvement in cases with nephrotic syndrome and normal kidney functions. Most of the available data describe the occurrence of various forms of myocardial insult in the context of chronic nephrotic syndrome patients with elevated kidney functions.

Moreover, advanced echocardiographic techniques such as tissue Doppler imaging and speckle tracking echo echocardiography, offer a greater opportunity to assess the systolic and diastolic function of the LV. The assessment of segmental systolic function by STE leads to a better reflection of segmental contribution to the overall function, which makes it superior to the classic Mmode-derived EF.

The primary outcome parameter of this study is to confirm or rule out the presence of myocardial dysfunction in NS; while the secondary outcome parameter is to determine the best predictor of myocardial involvement in NS.

\section{Methods}

\section{Study subjects}

This case-control cross-sectional observational study was conducted from December 2019 to July 2020. Forty patients (group 1) with fulfilling the clinical and laboratory criteria of nephrotic syndrome during the initial episode (first four weeks of the disease onset during initial steroid therapy) [5] were enrolled from the nephrology unit in our institution's Children Hospital. The exclusion criteria were any preexisting arrhythmia, congenital or acquired heart disease, or any concurrent systemic disease (obesity, diabetes, and systemic lupus erythematosus) that might impair myocardial functions as well as any abnormal kidney functions. Forty age, sex, and body surface area matched controls (group 2) were included in the study to benchmark echocardiographic parameters.

\section{Study methods}

\section{History taking and physical examination}

Patients were subjected to a full clinical history including data from age and sex as well as the onset of nephrotic syndrome, duration, and response to steroid use. Physical examination by a nephrologist included a blood pressure (BP) assessment and anthropometric data were collected to include weight and height.

\section{Biochemical assessment}

Blood-EDTA were immediately centrifuged $(20 \mathrm{~min}$, $2500 \mathrm{rpm}, 4{ }^{\circ} \mathrm{C}$ ), and plasma was stored at $-80{ }^{\circ} \mathrm{C}$ until use. Serum albumin, cholesterol, creatinine, and urea were evaluated in the clinical pathology department of our institution's Children Hospital.

\section{Echocardiographic assessment}

Transthoracic echocardiography was performed using a General Electric (Vivid-7/9, Horten, Norway) machine with 3- and 5-MHz transducers according to the age of the patient. It also has tissue velocity imaging capabilities.

- Conventional echocardiography included motionmode and Doppler echocardiographic parameters averaged over 3 cardiac cycles. All measurements were performed according to the guidelines for performance of echocardiogram by the American Society of Echocardiography [6]. Left ventricular fraction shortening and ejection fraction were calculated according to the Teichholz method [7].

- Conventional and tissue doppler imaging (TDI) was utilized to assess LV diastolic function by calculating the $\mathrm{LV} \mathrm{E} / \mathrm{e}^{\prime}$ ratio: the ratio between the early transmitral filling (E) and average early diastolic mitral annular and basal septal velocities. For statistical purposes, an $\mathrm{LV} \mathrm{E} / \mathrm{e}^{\prime}$ ratio $\geq 9$ was considered suggestive of diastolic dysfunction [8] 


\section{Three-dimensional echocardiography}

Full-volume acquisition of the left ventricle was obtained by harmonic imaging from the apical approach. Six ECG-gated consecutive beats were acquired during endexpiratory breath-hold to left ventricular full volume. The software automatically identified the Left Ventricular cavity endocardial border. The operator performed all the necessary adjustments manually in order to correctly place the endocardial border. After the adjustments, the software provided the left ventricular volumes, ejection fraction, and three-dimensionalderived global longitudinal strain. For statistical purposes, an LV GLS ratio $\leq 15$ was considered suggestive of systolic dysfunction [9].

\section{Statistical analysis}

Data were analyzed using IBM $\odot$ (International Business Machines) SPSS $\odot$ (The Statistical Package for the Social Sciences) Statistics version 23 (Armonk, New York, United States of America).

Normally distributed numerical variables were presented as mean and Standard Deviation and inter-group differences were compared using the unpaired $t$ test.

Scatter plots were designed to express the relationship between serum albumin on one hand and LV GLS and $\mathrm{LV} E / \mathrm{e}^{\prime}$ ratio on the other hand.

A $P$-value $<0.05$ was considered statistically significant.

\section{Results}

Table 1 shows the demographic criteria of cases and controls, cases were matched for age, sex, height, and weight compared to controls. The cases' weight was non-significantly higher than that of controls, probably due to edema.

Table 2 shows a comparison between basic and advanced echocardiographic parameters between the two study groups: speckle tracking echocardiography (STE) and tissue Doppler imaging (TDI). Diastolic dysfunction was observed in cases compared to controls as shown by a significantly higher LV E/e' (NS: $10 \pm 3$ vs. Controls: $5 \pm$ 1.9). LV GLS was reduced in cases compared to controls significant of LV systolic dysfunction (NS:17 \pm 1 vs. controls: $23 \pm 1$ ). Conventional FS was not significantly different between cases and controls.

In Table 3, cases were based on the presence or the absence of LV systolic dysfunction, into two groups (group 1A and group 1B). This is to compare the time of assessment from the onset of NS, and the duration of steroid therapy at the time of assessment as well as the baseline and follow-up serum cholesterol, serum albumin, and urine $\mathrm{P} / \mathrm{C}$ ratio and the echocardiographic data. No significant difference was observed in the duration and dose of steroid therapy or in the duration of the illness at the time of assessment. The baseline serum albumin, cholesterol, and urine $\mathrm{P} / \mathrm{C}$ ratio did not differ between the two study groups, whereas the serum albu$\mathrm{min}$ and urine $\mathrm{P} / \mathrm{C}$ ratio as well as the weight difference (reflective of response to treatment and improvement of hypoalbuminemia) were significantly different between the two subgroups at the time of assessment with the serum albumin being lower and the urine $\mathrm{P} / \mathrm{C}$ ratio higher in cases with systolic myocardial dysfunction at the time of assessment with lack of subsequent weight loss. This probably reflects a poorer response to steroid therapy with persistent hypoalbuminemia after two weeks of therapy.

Table 4 also divided the patients into two subgroups based on the presence or absence of LV diastolic dysfunction. Similar to Table 3, no significant difference was found in biochemical data and duration of steroid therapy between the two study groups except for the serum albumin and urine $\mathrm{P} / \mathrm{C}$ ratio at the time of assessment and weight difference. The findings shown in Tables 3 and 4 suggest that there might be a close relationship between hypoalbuminemia and the occurrence of systo-diastolic myocardial dysfunction, while steroid therapy seems to be unchanged between cases with Systolic or Diastolic dysfunction and cases with preserved function.

Table 5 is a multivariate analysis of the best predictors of LV GLS and LV E/e' ratio, serum albumin was the best predictor of both parameters, while duration and dose of steroid therapy did not achieve any statistical

Table 1 Demographic criteria of cases and controls

\begin{tabular}{llll}
\hline Variable & Nephrotic syndrome $(\boldsymbol{n}=\mathbf{4 0})$ & Control $(\boldsymbol{n}=\mathbf{4 0})$ & $\boldsymbol{P}_{\text {-value* }}$ \\
\hline Age (years) & $9.35 \pm 3.32$ & $9.69 \pm 4.35$ & 0.42 \\
Weight $(\mathrm{kg})$ & $49.04 \pm 11.03$ & $45.10 \pm 16.31$ & 0.07 \\
Height $(\mathrm{m})$ & $1.32 \pm 0.21$ & $1.39 \pm 0.17$ & 0.35 \\
Gender (M/F) & $24 / 16$ & $15 / 15$ & 0.624 \\
Systolic Blood pressure (mmHg) & $102 \pm 10$ & $109 \pm 12$ & 0.04 \\
Diastolic Blood Pressure $(\mathrm{mmHg})$ & $65 \pm 5$ & $71 \pm 4$ & 0.03 \\
\hline
\end{tabular}

Abbreviations: $F$ Female, kg kilogram, $m$ meter, $M$ Male, $m m H g$ millimeter mercury, $n$ number, $P$ Pearson's coefficient of statistical significance)

$P<0.05$ was considered statistically significant 
Table 2 Left ventricular echocardiographic parameters in cases vs. controls

\begin{tabular}{|c|c|c|c|}
\hline \multirow[t]{2}{*}{ Variable } & \multirow{2}{*}{$\begin{array}{l}\text { Nephrotic syndrome }(n=40) \\
\text { Mean } \pm \text { SD }\end{array}$} & \multirow{2}{*}{$\begin{array}{l}\text { Control }(n=40) \\
\text { Mean } \pm \text { SD }\end{array}$} & \multirow[t]{2}{*}{$P$-value } \\
\hline & & & \\
\hline 3D LVEDV (ml) & $59.53 \pm 18.75$ & $58.59 \pm 36.21$ & 0.45 \\
\hline 3D EF (\%) & $78.00 \pm 7.69$ & $79.24 \pm 6.53$ & 0.33 \\
\hline FS (\%) & $46.33 \pm 7.35$ & $47.17 \pm 3.59$ & 0.23 \\
\hline GLS (\%) & $17.39 \pm 6.45$ & $23.86 \pm 1.41$ & $<0.0001$ \\
\hline$E / e^{\prime}$ & $10.25 \pm 3.44$ & $5.90 \pm 1.29$ & $<0.0001$ \\
\hline
\end{tabular}

Abbreviations: $E / e^{\prime}$ ratio of diastolic function of LV; ratio of early transmitral inflow to average early diastolic velocities of mitral annulus and basal septum, $E F$ Ejection fraction, FS Fractional shortening), GLS Global longitudinal strain, $L V$ Left ventricle, $n$ number, $P$ Pearson's coefficient for statistical significance $P<0.05$ was considered statistically significant

significance in predicting each of the systolic or diastolic dysfunction of the LV, which goes in agreement with the findings elicited in Tables 3 and 4.

Figures 1 and 2 are two scatter plots showing the relationship between serum albumin on one hand and both GLS and LV E/e' ratio on the other hand. There was a significant positive correlation between GLS and serum albumin while a negative correlation was found between $\mathrm{LV}$ E/e' ratio and serum albumin.

\section{Discussion}

It is widely recognized that NS is the commonest kidney disorder in the pediatric age group. It is characterized by massive proteinuria and dyslipidemia mainly involving

Table 3 Duration of nephrotic syndrome, steroid therapy, laboratory, and echocardiographic data in cases with systolic dysfunction vs. cases without

\begin{tabular}{|c|c|c|c|}
\hline & $\begin{array}{l}\text { Nephrotic syndrome with } \\
\text { impaired GLS }(n=17)\end{array}$ & $\begin{array}{l}\text { Nephrotic syndrome with } \\
\text { normal GLS }(n=23)\end{array}$ & $\begin{array}{l}P \text { - } \\
\text { value }\end{array}$ \\
\hline & Mean \pm SD & Mean \pm SD & \\
\hline Serum creatinine at the time of assessment $(\mathrm{mg} / \mathrm{dL})$ & $0.8 \pm 0.05$ & $0.79 \pm 0.04$ & 0.56 \\
\hline Serum urea at the time of assessment $(\mathrm{mg} / \mathrm{dL})$ & $14 \pm 2$ & $12 \pm 3$ & 0.66 \\
\hline Serum baseline cholesterol (mg/dL) & $226 \pm 12$ & $232 \pm 10$ & 0.56 \\
\hline Serum cholesterol at the time of assessment $(\mathrm{mg} / \mathrm{dL})$ & $177 \pm 21$ & $173 \pm 20$ & 0.72 \\
\hline Serum baseline albumin (gm/dL) & $2.2 \pm 0.1$ & $2.3 \pm 0.2$ & 0.56 \\
\hline Serum albumin at the time of assessement ( $\mathrm{gm} / \mathrm{dL})$ & $2.4 \pm 0.3$ & $2.9 \pm 0.1$ & $\begin{array}{l}< \\
0.001\end{array}$ \\
\hline Baseline urine $\mathrm{P} / \mathrm{C}$ ratio & $6 \pm 0.9$ & $5 \pm 1$ & 0.65 \\
\hline Urine $\mathrm{P} / \mathrm{C}$ ratio at the time of assessment & $3 \pm 0.7$ & $1.4 \pm 0.4$ & $\begin{array}{l}< \\
0.001\end{array}$ \\
\hline $\begin{array}{l}\text { Duration from onset of NS to time of assessment by } \\
\text { echocardiography (weeks) }\end{array}$ & $16 \pm 1$ & $14 \pm 2$ & 0.39 \\
\hline Duration of steroid therapy (weeks) & $14.8 \pm 2$ & $15.9 \pm 3$ & 0.5 \\
\hline Dose of steroid (mg/kg/day) & $2 \pm 0$ & $2 \pm 0$ & 0.9 \\
\hline Weight difference from the onset to time of assessment $(\mathrm{kg})$ & $2.2 \pm 0.2$ & $3.1 \pm 0.3$ & $\begin{array}{l}< \\
0.001\end{array}$ \\
\hline 3D LVEDV (ml) & $61 \pm 12$ & $58 \pm 22$ & 0.45 \\
\hline 3D EF (\%) & $77 \pm 3.2$ & $79 \pm 4$ & 0.40 \\
\hline FS (\%) & $46 \pm 2$ & $46 \pm 3$ & 0.23 \\
\hline GLS (\%) & $14 \pm 3.2$ & $18 \pm 1.41$ & $\begin{array}{l}< \\
0.0001\end{array}$ \\
\hline$E / e^{\prime}$ & $12 \pm 2$ & $8 \pm 1.29$ & $\begin{array}{l}< \\
0.0001\end{array}$ \\
\hline
\end{tabular}

Abbreviations: $E / e^{\prime}$ ratio of diastolic function of LV; ratio of early transmitral inflow to average early diastolic velocities of mitral annulus and basal septum, EDV End diastolic volume, EF Ejection fraction, FS Fractional shortening, GLS Global longitudinal strain, $L V$ Left ventricle, $n$ number, $P / C$ ratio protein creatinine ratio, $P$ Pearson's coefficient for statistical significance

$P<0.05$ was considered statistically significant 
Table 4 Duration of nephrotic syndrome, steroid therapy, laboratory, and echocardiographic data in cases with diastolic dysfunction dysfunction vs. cases without

\begin{tabular}{|c|c|c|c|}
\hline & $\begin{array}{l}\text { Nephrotic syndrome with impaired } \\
\text { diastolic function }(n=18)\end{array}$ & $\begin{array}{l}\text { Nephrotic Syndrome with normal } \\
\text { diastolic function }(n=22)\end{array}$ & $\begin{array}{l}P \text { - } \\
\text { value }\end{array}$ \\
\hline & Mean \pm SD & Mean \pm SD & \\
\hline $\begin{array}{l}\text { Serum creatinine at the time of assessment (mg/ } \\
\mathrm{dL} \text { ) }\end{array}$ & $0.79 \pm 0.04$ & $0.8 \pm 0.04$ & 0.44 \\
\hline Serum urea at the time of assessment $(\mathrm{mg} / \mathrm{dL})$ & $14 \pm 1.9$ & $12 \pm 3.1$ & 0.65 \\
\hline Serum baseline cholesterol (mg/dL) & $229 \pm 11$ & $231 \pm 10$ & 0.43 \\
\hline $\begin{array}{l}\text { Serum cholesterol at the time of assessment (mg/ } \\
\mathrm{dL} \text { ) }\end{array}$ & $175 \pm 193$ & $175 \pm 19$ & 0.78 \\
\hline Serum baseline albumin (gm/dL) & $2.1 \pm 0.2$ & $2.2 \pm 0.2$ & 0.59 \\
\hline Serum albumin at the time of assessement $(\mathrm{gm} / \mathrm{dL})$ & $2.4 \pm 0.2$ & $2.8 \pm 0.1$ & $\begin{array}{l}< \\
0.001\end{array}$ \\
\hline Baseline urine $\mathrm{P} / \mathrm{C}$ ratio & $6 \pm 0.8$ & $5.2 \pm 0.5$ & 0.68 \\
\hline Urine $\mathrm{P} / \mathrm{C}$ ratio at the time of assessment & $2.9 \pm 0.6$ & $1.5 \pm 0.3$ & $\begin{array}{l}< \\
0.001\end{array}$ \\
\hline $\begin{array}{l}\text { Duration from onset of NS to time of assessment } \\
\text { by echocardiography (weeks) }\end{array}$ & $14.9 \pm 2$ & $15.9 \pm 1$ & 0.07 \\
\hline Duration of steroid therapy (weeks) & $15 \pm 2$ & $12 \pm 1$ & 0.44 \\
\hline Dose of steroid & $2 \pm 0$ & $2 \pm 0$ & 0.78 \\
\hline $\begin{array}{l}\text { Weight difference from the onset to time of } \\
\text { assessment }(\mathrm{kg})\end{array}$ & $2.3 \pm 0.3$ & $3.1 \pm 0.3$ & $\begin{array}{l}< \\
0.001\end{array}$ \\
\hline 3D LVEDV (ml) & $60 \pm 8$ & $59 \pm 13$ & 0.42 \\
\hline 3D EF (\%) & $78 \pm 2.5$ & $79 \pm 3.1$ & 0.33 \\
\hline FS (\%) & $46 \pm 3$ & $46 \pm 2$ & 0.39 \\
\hline GLS (\%) & $15 \pm 3.2$ & $19 \pm 1.41$ & $\begin{array}{l}< \\
0.0001\end{array}$ \\
\hline$E / e^{\prime}$ & $13 \pm 3$ & $8 \pm 2$ & $\begin{array}{l}< \\
0.0001\end{array}$ \\
\hline
\end{tabular}

Abbreviations: $E / e^{\prime}$ ratio of diastolic function of LV; ratio of early transmitral inflow to average early diastolic velocities of mitral annulus and basal septum, $E F$ Ejection fraction, FS Fractional shortening, GLS Global longitudinal strain, $L V$ Left ventricle, $n$ number, $P$ Pearson's coefficient for statistical significance

$P<0.05$ was considered statistically significant

hypercholesterolemia. Myocardial injury in new-onset NS is an understudied field. To our knowledge, the series studying the effect of NS on the cardiovascular system have mainly tackled myocardial injury in the context of chronic NS $[2,10]$. Another recent point of focus has been the increased risk of coronary hypoperfusion in NS $[11,12]$.

Our report is by far the first to study the effect of new-onset NS on myocardial involvement. Our study subjects showed statistically significant systo-diastolic

Table 5 Multivariate analysis for the predictors of systolic and diastolic function of LV in nephrotic syndrome

\begin{tabular}{|c|c|c|c|c|}
\hline & \multicolumn{2}{|c|}{ LV GLS (\%) } & \multicolumn{2}{|c|}{ LV E/e' } \\
\hline & $\bar{R}$ & $P$ & $\bar{R}$ & $P$ \\
\hline Duration of initial episode of nephrotic syndrome (days) & 0.12 & 0.2 & 0.13 & 0.18 \\
\hline Serum albumin (g/dL) & 0.38 & $<0.001$ & 0.44 & $<0.001$ \\
\hline Serum cholesterol (mg/dL) & 0.22 & 0.14 & 0.23 & 0.11 \\
\hline Systolic blood pressure (mmHg) & 0.11 & 0.3 & 0.21 & 0.15 \\
\hline Diastolic blood pressure $(\mathrm{mmHg})$ & 0.24 & 0.11 & 0.25 & 0.09 \\
\hline Duration of steroid therapy & -0.22 & 0.24 & -0.12 & 0.7 \\
\hline
\end{tabular}

Abbreviations: $d L$ deciliter, $E / e^{\prime}$ ratio of diastolic function of $\mathrm{LV}$; ratio of early transmitral inflow to average early diastolic velocities of mitral annulus and basal septum, $g$ gram, GLS Global longitudinal strain, $L V$ Left ventricle, $\mathrm{mg}$ milligram, $\mathrm{mmHg}$ millimeter mercury, $P$ Pearson's coefficient of statistical significance, $R$ correlation coefficient

$P<0.05$ was considered statistically significant 


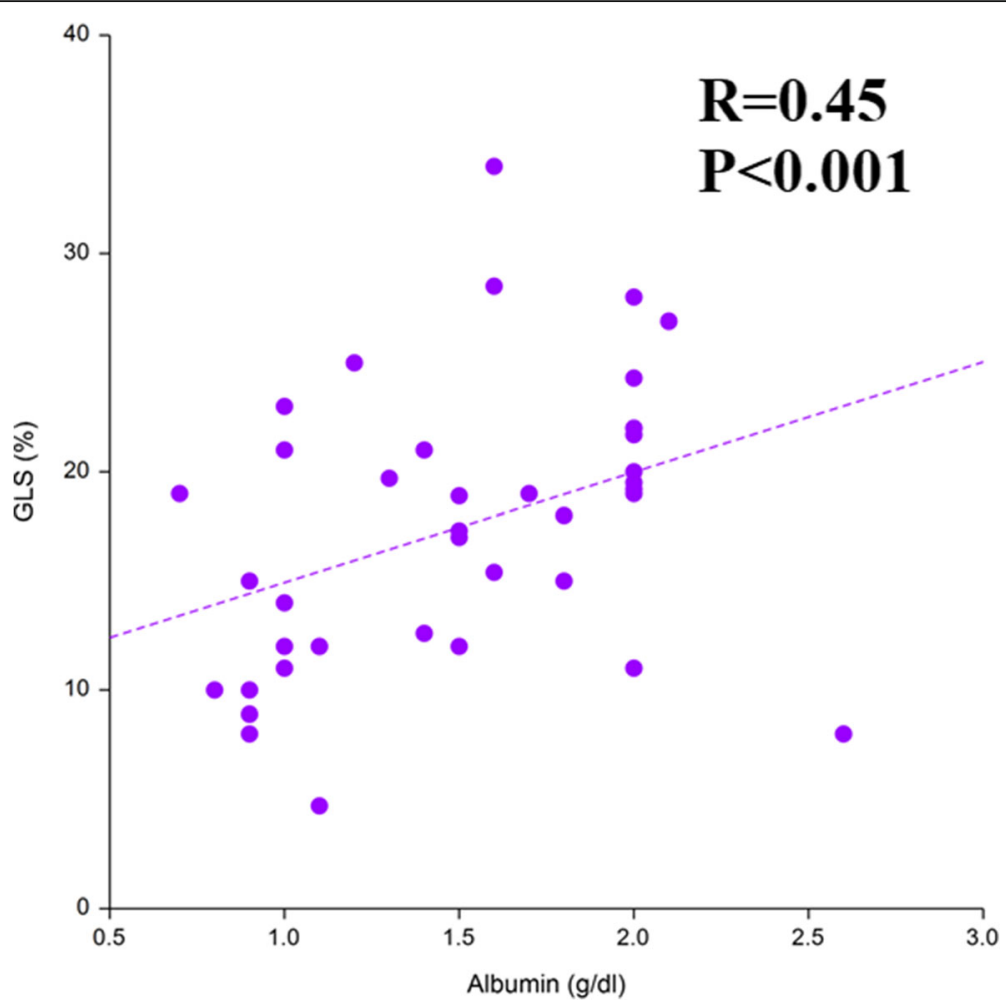

Fig. 1 Scatter plot showing relationship between LV GLS and serum albumin. Abbreviations: LV, left ventricular; GLS, global longitudinal strain

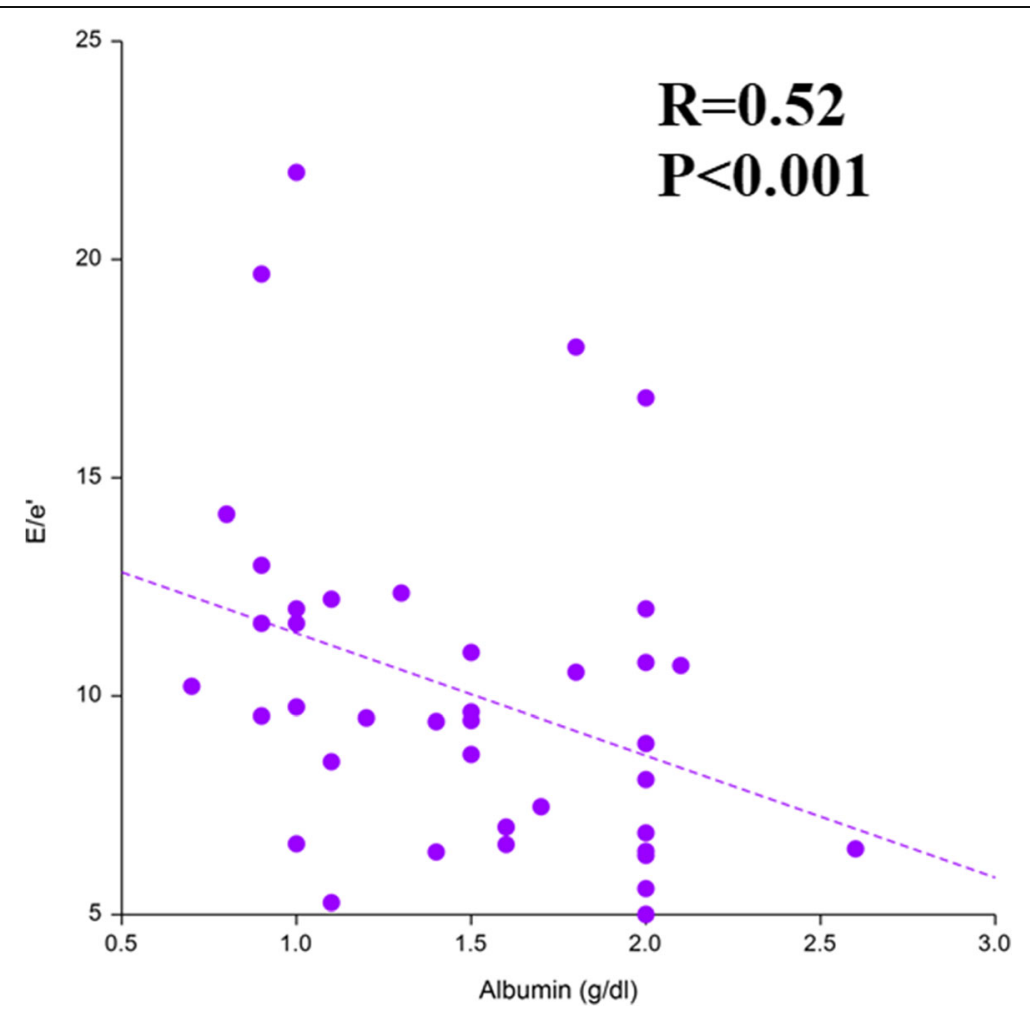

Fig. 2 Scatter plot showing the relationship between E/e' ratio and serum albumin. Abbreviations: E/e', ratio between early transmitral inflow velocity and average early diastolic mitral annular and basal septal velocities 
dysfunction compared to controls. Unlike the previously fixed belief that dyslipidemia, notably hypercholesterolemia associated with NS is the commonest predisposing factor for myocardial involvement, our multivariate analysis shows that serum cholesterol failed to be a statistically significant predictor of either systolic or diastolic dysfunction in NS [13].

Likewise, steroid use was thought to be an important inducer of myocardial dysfunction, specifically proved in animal models and in humans as well. Bauer and associates succeeded in demonstrating that steroid intake for 8 weeks at a dose of $5 \mathrm{mg} / \mathrm{kg} /$ day induces deterioration of myocardial dysfunction in mouse models. Bispo and colleagues also demonstrated myocardial insult in a case report of a patient receiving anabolic steroids for 10 weeks. Our study, however, failed to show any relationship between steroid use and the observed myocardial dysfunction. This might be due to the lower dose of steroids compared to the mentioned series $(2 \mathrm{mg} / \mathrm{kg} /$ day $)$. Another factor that might be implicated in the absence of the steroid effect is the relatively short period of steroid use compared to the Bauer and Bispo series. The average duration of steroid use was 4 weeks, while the duration of steroid use needed to induce myocardial dysfunction seems to be close to 8-10 weeks [14, 15].

The only significant predictor of myocardial injury in NS was serum albumin. Serum albumin was found to be negatively correlated with $\mathrm{LV} E / \mathrm{e}^{\prime}$ ratio and positively correlated with LV GLS. The contribution of serum albumin to myocardial dysfunction during the initial episode of NS seems to be a virgin piece of land.

Several possible explanations can be offered to justify the role of decreased albumin in inducing myocardial dysfunction in the context of NS. The first of which is the major role of albumin in scavenging free oxygen radicals and decreasing inflammation. Furthermore, Hara et al. [3] correlated the levels of proteinuria with inflammatory markers in patients with Lymphoma and concluded that higher proteinuria is associated with higher levels of acute-phase reactants in non-Hodgkin lymphoma. On top of that, Dirajlal-Fargo and colleagues reported that decreased albumin can be an important pathogenic factor in the inflammatory process leading to the development of carotid atherosclerosis [16]. The persistent hypoalbuminemia in cases showing myocardial dysfunction was coupled with persistent albuminuria and failure of significant weight loss suggesting early evidence of failure of response to steroids.

Finally, yet importantly, hypoalbuminemia has been implicated in the induction of endothelial dysfunction. Yu et al. [13] underlined the role of albumin leak in the development of microvascular injury in peritoneal dialysis patients. Nevertheless, Caraba and colleagues proved that there is a state of endothelial dysfunction in NS patients. Such endothelial dysfunction might impair coronary perfusion leading to subsequent ventricular dysfunction [17].

\section{Conclusion}

This paper points at early myocardial injury in cases with NS. Hypoalbuminemia seems to play a central role in the induction of such dysfunction. Despite the known role of steroid use in triggering such dysfunction, the relatively short duration and a low dose of steroid use in our study subjects wasn't enough to justify this role. Furthermore, Hypoalbuminemia might be operating either through triggering myocardial inflammation or through impairing myocardial perfusion via endothelial dysfunction. Further studies are needed to unleash the mechanisms by which hypoalbuminemia operate to induce myocardial dysfunction.

\section{Abbreviations}

BP: Blood Pressure; ECG: Electrocardiogram; GLS: Global longitudinal strain; LV: Left ventricle; LV E/e': The ratio between the early transmitral filling (E) and average early diastolic mitral annular and basal septal velocities; NS: Nephrotic syndrome; STE: Speckle tracking echocardiography; TDI: Tissue Doppler imaging

\section{Acknowledgements}

To our families who are bearing the weight of our sacrifice of time to our patients. If our families were not understanding to the depth of our struggle, we would have never been able to keep the same level of dedication to our patients. To our students that we involve in each step of our researches to make them flourish in this field and take the lead the soonest the possible.

\section{Authors' contributions}

M.H conceived the idea, A.S revised the patients' selection, S.Y and M.T participated in data collection, A.A and M.S performed and interpreted Echocardiography. All authors read and approved the final manuscript.

\section{Availability of data and materials}

The datasets used and/or analyzed during the current study are available from the corresponding author on reasonable request.

\section{Declarations}

Ethics approval and consent to participate

The authors assert that all procedures contributing to this work comply with the ethical standards of the relevant Egyptian guidelines on human experimentation and with the Helsinki Declaration of 1975, as revised in 2008, and has been approved by the institutional committee of the Faculty of Medicine, Cairo University. Ethical committee approval number is: I231546. A written consent was fulfilled by each of the study participants.

\section{Consent for publication}

Not applicable.

\section{Competing interests}

The authors declare that they have no competing interests.

\section{Author details}

${ }^{1}$ Pediatrics Department, Pediatric Cardiology unit, Faculty of Medicine, Cairo University, Manial Street, Cairo, Egypt. ²Pediatric Cardio-Oncology Department, Children Cancer Hospital of Egypt, Cairo, Egypt. ${ }^{3}$ Pediatrics Department, Pediatric Neurology Unit, Faculty of Medicine, Cairo University, Cairo, Egypt. ${ }^{4}$ Residency Program, Faculty of Medicine, Cairo University, Cairo, Egypt. ${ }^{5}$ Pediatrics Department, Pediatric Nephrology Unit, Faculty of Medicine, Cairo University, Cairo, Egypt. 
Received: 17 August 2020 Accepted: 24 August 2021

Published online: 18 October 2021

\section{References}

1. Wang C, Greenbaum LA (2019) Nephrotic syndrome. Pediatr Clin North Am. https://doi.org/10.1016/j.pcl.2018.08.006

2. Moreira-Rodrigues M, Roncon-Albuquerque R Jr, Henriques-Coelho T, Lourenço AP, Sampaio-Maia B, Santos J, Pestana M, Leite-Moreira AF (2007) Cardiac remodeling and dysfunction in nephrotic syndrome. Kidney Int. 71(12):1240-1248. https://doi.org/10.1038/sj.ki.5002204

3. Hara M, Ando M, Maeda Y, Tsuchiya K, Nitta K (2014) Proteinuria is a simple sign of systemic inflammation that leads to a poor prognosis in individuals affected with non-Hodgkin lymphoma. Clin Nephrol. https://doi.org/10. 5414/CN108132

4. Shokr M, Rashed A, Lata K, Kondur A (2016) Dexamethasone associated ST elevation myocardial infarction four days after an unremarkable coronary angiogram - another reason for cautious use of steroids: a case report and review of the literature. Case Reports Cardiol. 2016:1-6. https://doi.org/10.11 $55 / 2016 / 4970858$

5. Bagga A (2008) Revised guidelines for management of steroid-sensitive nephrotic syndrome. Indian J Nephrol. 18(1):31-39. https://doi.org/10.4103/ 0971-4065.41289

6. Cheitlin MD, Armstrong WF, Aurigemma GP, Beller GA, Bierman FZ, Davis $J$, Douglas PS, Faxon DP, Gillam LD, Kimball TR, Kussmaul WG, Pearlman AS, Philbrick JT, Rakowski H, Thys DM, Antman EM, Smith SC Jr, Alpert JS, Gregoratos G, Anderson JL, Hiratzka LF, Faxon DP, Hunt SA, Fuster V, Jacobs AK, Gibbons RJ, Russell RO, ACC, AHA, ASE (2003) ACC/AHA/ASE 2003 guideline update for the clinical application of echocardiography: summary article. J Ame Society Echocardiography 16(10):1091-1110. https://doi.org/1 0.1016/S0894-7317(03)00685-0

7. Teichholz LE, Kreulen T, Herman MV, Gorlin R (1976) Problems in echocardiographic volume determinations: echocardiographic-angiographic correlations in the presence or absence of asynergy. Am J Cardiol. 37(1):711. https://doi.org/10.1016/0002-9149(76)90491-4

8. Nagueh SF, Smiseth OA, Appleton CP, Byrd BF III, Dokainish H, Edvardsen T, Flachskampf FA, Gillebert TC, Klein AL, Lancellotti P, Marino P, Oh JK, Popescu BA, Waggoner AD (2016) Recommendations for the evaluation of left ventricular diastolic function by echocardiography: an update from the American Society of Echocardiography and the European Association of Cardiovascular Imaging. J Am Soc Echocardiogr. 29(4):277-314. https://doi. org/10.1016/j.echo.2016.01.011

9. Bolog M, Dumitrescu M, Pacuraru E, Romanoschi F (2017) Cut off value of rest left ventricular global longitudinal strain is important in selecting high risk patients with stable symptoms and normal left ventricular systolic function. J Am Coll Cardiol. 69(11):1471. https://doi.org/10.1016/S0735-1 097(17)34860-X

10. Saleh SM, Mahmoud Elmaghraby KS, Abdelfadil AM, Mohamed HS (2018) Myocardial performance index in nephrotic syndrome. J Clin Exp Cardiolog. 09:2-7

11. Artery C, Cad D (2020) Nephrotic syndrome as an underrecognized risk factor for coronary artery disease (cad), pp 2-3. https://doi.org/10.1001/a rchinte.168.9.987.2

12. Patnaik SK et al (2018) Cardiovascular outcomes of Nephrotic syndrome in childhood (CVONS) study: a protocol for prospective cohort study. BMC Nephrol. 19:1-10

13. Hari P, Khandelwal P, Smoyer WE (2019) Dyslipidemia and cardiovascular health in childhood nephrotic syndrome. Pediatr Nephrol. 35(9):1601-1619. https://doi.org/10.1007/s00467-019-04301-y

14. Bauer R, MacGowan GA, Blain A, Bushby K, Straub V (2008) Steroid treatment causes deterioration of myocardial function in the -sarcoglycandeficient mouse model for dilated cardiomyopathy. Cardiovasc Res. 79(4): 652-661. https://doi.org/10.1093/cvr/cvn131

15. Bispo M, Valente A, Maldonado R, Palma R, Glória H, Nóbrega J, Alexandrino P (2009) Anabolic steroid-induced cardiomyopathy underlying acute liver failure in a young bodybuilder. World J Gastroenterol. 15(23):2920-2922. https://doi.org/10.3748/wjg.15.2920

16. Dirajlal-Fargo $S$ et al (2018) Serum albumin is associated with higher inflammation and carotid atherosclerosis in treated human immunodeficiency virus infection. Open Forum Infect Dis 5:1-9

17. Caraba A, Romoşan I (2007) Endothelial dysfunction in the nephrotic syndrome. Med Pregl 60(Suppl 2):66-69

\section{Publisher's Note}

Springer Nature remains neutral with regard to jurisdictional claims in published maps and institutional affiliations.

\section{Submit your manuscript to a SpringerOpen ${ }^{\circ}$ journal and benefit from:}

- Convenient online submission

- Rigorous peer review

- Open access: articles freely available online

- High visibility within the field

- Retaining the copyright to your article

Submit your next manuscript at $\boldsymbol{\nabla}$ springeropen.com 